\title{
INTRODUCTION
}

\section{New models of inclusive innovation for development}

\author{
Richard Heeks ${ }^{\mathrm{a} *}$, Christopher Foster ${ }^{\mathrm{b}}$ and Yanuar Nugroho ${ }^{\mathrm{a}, \mathrm{c}}$ \\ ${ }^{a}$ Centre for Development Informatics, University of Manchester, Manchester M13 9PL, UK; ${ }^{b}$ Oxford \\ Internet Institute, University of Oxford, 1 St Giles', Oxford OXI 3JS, UK; ${ }^{c}$ Manchester Institute of \\ Innovation Research, Manchester Business School, University of Manchester, Manchester M13 9PL, UK
}

\begin{abstract}
This special issue of Innovation and Development focuses on inclusive innovation; specifically on analysis of the new models of this form of innovation which are emerging. After discussing the growing need for research into those models, this editorial paper interrogates the meaning of 'inclusive innovation' and what it means to understand inclusive innovation in terms of models. The editorial then outlines the contribution of the papers that make up this special issue before drawing out some lessons for inclusive innovation policy and practice, and discussing future research priorities.
\end{abstract}

Keywords: inclusive innovation; mainstream innovation; innovation platforms; grassroots innovation; cluster innovation; user-producer relations; frugal innovation

\section{Introduction}

If the focus of this special issue is on new models of inclusive innovation then, inherently, there must have been some old models that form the basis for comparison. There are two such foundations. First, there is an old model of what, for contrast's sake, we can call 'mainstream innovation'. This is the innovation aimed at middle- and high-income consumers, producing new goods and services that improve the welfare of those consumers and/or producing new processes that improve the productivity of formal producers. By improving the welfare of higher-income consumers but not that of more marginalized consumers, by improving the productivity of formal but not informal producers, and by focusing on economic development rather than social development needs, mainstream innovation was and remains an innovation of inequality (Klochikhin 2012; OECD 2013).

Concerns about these shortcomings of mainstream innovation have led to a search for alternatives. There is nothing new about this, and these older models of inclusive innovation form a second foundation for comparison. One can trace a line from Robert Owen through Lewis Mumford and Mahatma Gandhi to Ernst Schumacher and the debates of the 1970s about appropriate technology; all of which sought to develop alternative models of innovation that would address the needs of those excluded from the fruits of mainstream innovation (Jamison 2006).

But in the past decade or so, there have been a number of changes that can justify the notion that we might identify new models of innovation for development (Heeks et al. 2013):

\footnotetext{
*Corresponding author. Email: richard.heeks@manchester.ac.uk
} 
- significant involvement of the private sector and global value chains in innovation for the poor,

- the development of poor consumers as an accessible mass market,

- growth of technological capabilities within developing countries, and

- the involvement of new technologies especially information and communication technologies such as mobile phones.

These are some of the component parts of a growth in practices that have been given the label 'inclusive innovation' but which have also been given other labels including 'pro-poor innovation', 'below-the-radar innovation', 'grassroots innovation', 'BoP (base-of-the pyramid) innovation', and more (Kaplinsky 2011; Cozzens and Sutz 2012; Ramani, SadreGhazi, and Duysters 2012). Growth in the reality of this alternative or modified form of innovation has been matched by a growth of political and academic interest, driven particularly by both an actuality and a heightened perception of rising inequality. That inequality - as well as being inherently problematic - is also seen as holding back social and economic development in the long run (Stiglitz 2012). Models of innovation have been drawn into this focus on 'inclusive development' (UNDP 2014) or 'shared prosperity' (World Bank 2013a) because, as noted, mainstream innovation is associated with increasing inequality while inclusive innovation is associated with reduced inequality (Cozzens et al. 2007; Lazonick and Mazzucato 2013).

We therefore see growing engagement with inclusive innovation by international organizations such as the World Bank (Goel 2011) and OECD (2013), by national governments such as India (OAPM 2011) and China (World Bank 2012), and by multinationals from global North and South such as Unilever and Tata (Chataway, Hanlin, and Kaplinsky 2014) alongside large- and medium-sized firms. Hand-in-hand with this activity has grown an intellectual engagement with inclusive innovation. Clusters of intellectual activity are reflected in journal special issues - this current issue plus also ones on 'Innovation for Inclusive Growth' (George, McGahan, and Prabhu 2012) and 'Innovation for Inclusive Development' (Santiago 2014). Figure 1 summarizes more general growth in intellectual outputs on the topic. ${ }^{1}$

We can have a reasonable degree of confidence that inclusive innovation will continue to be of importance in future. A content analysis has been undertaken comparing the key texts for the Millennium Development Goals (MDGs) with those for the Post-2015 Development Agenda, in order to pinpoint issues which are rising up or falling down the international development agenda (Heeks 2014). The concept of innovation more than triples its presence within the development discourse from MDGs to post-2015, while inclusivity increases by more than $1000 \%$.

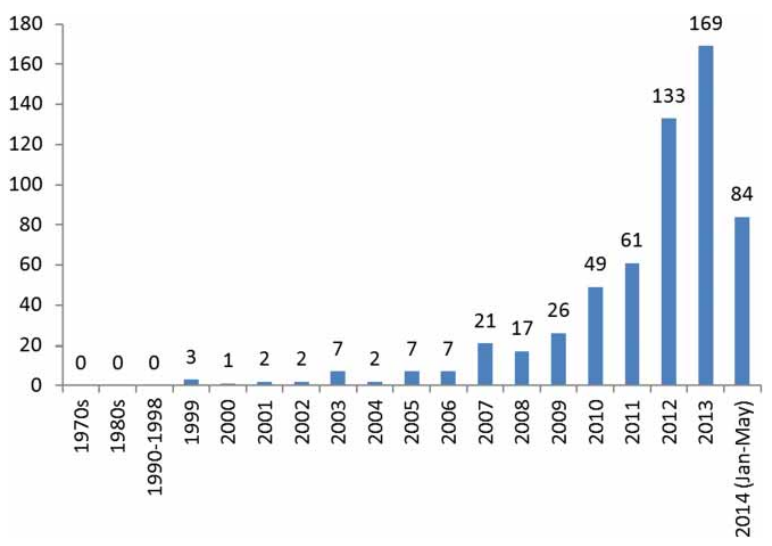

Figure 1. Growth in intellectual outputs on inclusive innovation. 
Their intersection - inclusive innovation - will therefore play an even greater role in development in future than it has done to date.

\section{Understanding inclusive innovation}

We can divide the content of the literature on inclusive innovation into three categories. Descriptive material just portrays examples of inclusive innovation. Analytical material investigates inclusive innovation through some conceptual lens or framework. Prescriptive material provides guidance on inclusive innovation; running from good implementation practices to arguments about moral framing.

In broad terms, the growth of intellectual output reflected in Figure 1 has been strong on description and on experience-based prescription, but much weaker on analysis and on inquiry-based prescription. Without an analytical foundation, there are concerns that research will not create a critical mass of understanding, and that guidance for innovation policy and practice will be sub-optimal.

Recognition of this analysis gap has prompted a number of initiatives in recent years including the two journal special issues referred to above, one of which emerged from IDRC's short-lived research programme on Innovation for Inclusive Development (IDRC 2011). The analysis gap was also the catalyst for the University of Manchester to organize the July 2013 workshop on 'New Models of Innovation for Development', from which the inclusive innovation-focused papers in this special issue are drawn.

Various elements of inclusive innovation were seen to require further analysis, of which two will be discussed here. First, analysis of the concept of inclusive innovation, covered in this section. Second, analysis of new models of inclusive innovation, covered in the next section of this editorial.

Foster and Heeks $(2013,335)$ define inclusive innovation simply as 'the inclusion within some aspect of innovation of groups who are currently marginalised'. As Heeks et al. (2013) identify, this cues further discussion about two aspects of the definition in order to more-fully conceptualize inclusive innovation.

The first issue is that of identity: Which groups are seen as historically having been marginalized or excluded, and as needing to be included by new approaches to innovation? Groups identified as the focus for inclusive innovation include women, youth, the disabled, ethnic minorities, and informal sector entrepreneurs (Codagnone 2009; OECD 2013). But the main focus has been the poor: those on lowest incomes, which may typically be defined as less than US\$1.25 or US $\$ 2.00$ or US\$2.50 per day.

The second issue is which 'aspect' of innovation the marginalized group is to be included in. The main contrast is between those who think exclusion can be addressed simply in terms of innovation outputs vs. those who think marginalized groups must be included in innovation processes. A more differentiated view is shown in the 'ladder of inclusive innovation' (Figure 2, adapted from Heeks et al. 2013):

- 'Level 1/Intention: an innovation is inclusive if the intention of that innovation is to address the needs or wants or problems of the excluded group ...

- Level 2/Consumption: an innovation is inclusive if it is adopted and used by the excluded group ...

- Level 3/Impact: an innovation is inclusive if it has a positive impact on the livelihoods of the excluded group ...

- Level 4/Process: an innovation is inclusive if the excluded group is involved in the development of the innovation ... 


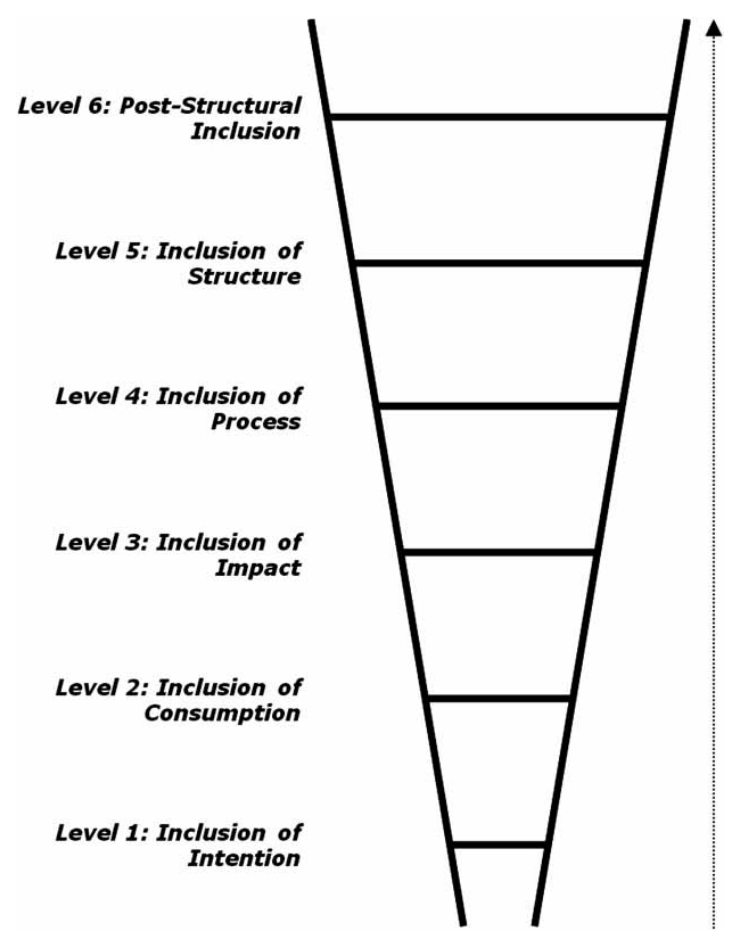

Figure 2. Understanding the different levels of inclusive innovation.

- Level 5/Structure: an innovation is inclusive if it is created within a structure that is itself inclusive...

- Level 6/Post-Structure: an innovation is inclusive if it is created within a frame of knowledge and discourse that is itself inclusive....

The levels are akin to steps on a ladder because each level involves a gradual deepening and/or broadening of the extent of inclusion of the excluded group in relation to innovation. In general, each level accepts the inclusion of the levels below, but pushes the extent of inclusion further.' (Heeks et al. 2013, 4-6)

There is no right or wrong 'focus' and 'level', but one needs to recognize within any text on inclusive innovation - be it a policy, public statement, or research paper - which group and which type of inclusion underpins that text. Particular conceptualizations will have particular implications. For example, different marginalized groups will have been subjected to different types of prior exclusion, with different histories and causes (Joseph 2014). Types of inclusion that work for one group will not necessarily work for others creating, for example, the potential for 'illusive inclusion'.

Similarly, the nature of what innovation is understood to be will vary depending on which level of the ladder is accepted as defining inclusive innovation. For the lower levels, innovation will be more of the conventional product/process type. For the higher levels, a broader scope of innovation must be encompassed. The most-recent version of the Oslo Manual (OECD 2005) arguably the principal global source for defining how we understand and measure the concept of innovation - has moved beyond just product/process to also embrace organizational and marketing changes as innovations. But full acceptance of some concepts of inclusive innovation may 
require a broader scope still, including quite minor adaptations and appropriations and use variations, and also recognizing that innovation occurs throughout the lifecycle of a new good or service from design through production to diffusion and use (Foster and Heeks 2013). At the highest level of the ladder, innovation may be broadened yet further to include a necessity for change in social structures, social discourse, and frames of knowledge.

\section{New models of inclusive innovation}

A model is an abstraction from, and a simplification of reality. Its aim may often be to help us understand that reality - which we otherwise could not do because 'true' realities are far too complex for the human mind to encompass - and through understanding, to potentially intervene more effectively.

A variety of new models of inclusive innovation is presented in this special issue, as described further in the next section:

- Innovation platforms (covered in the Swaans et al. and Cullen et al. papers in this special issue) are mechanisms to bring together a group of stakeholders with a focus on innovating to address a particular issue of common interest.

- Cluster innovation (Voeten and Naudé's paper) is innovation that takes place within a colocated group, in which the innovation cannot be attributed to any individual but to a process of group learning. Typically - as in this case - this is a group of micro-/small enterprise owners.

- User-producer interaction (Foster and Heeks' paper) focuses on the learning and innovation which occurs in the connection between producers and consumers.

- Grassroots innovation (papers by Fressoli et al. and Papaioannou) is innovation 'from below', generally associated with innovation emerging from low-income communities.

- Frugal innovation (Papaioannou paper) is innovation that seeks to minimize resource usage, cost and complexity in the production, constitution, and operation of new goods and services.

Models must be recognized as having both pros and cons. If they fulfil the aims stated above, they can make it easier to understand innovation, to communicate and discuss innovation, and to prioritize innovation interventions. But by including only some aspects of reality, they exclude others: while a model throws some elements of innovation into its spotlight, it casts others into shadow.

The very act of giving something a label and calling it a model also has an impact. What does it mean to qualify the word 'innovation' in some way, rather than just calling a phenomenon 'innovation' tout court? By giving a new label, do we give a higher profile and priority and more support to the activity? Or do we identify it as being different and liminal? From this, three perspectives on models of inclusive innovation emerged within the July 2013 workshop:

- Inherent Incorporation: the activities of inclusive innovation are already accepted as innovation, and need no additional label. Indeed, labelling may serve to marginalize.

- Deliberate Incorporation: although the activities of inclusive innovation are a form of innovation, they require a new 'innovation plus' label in order to justify their acceptance as innovation by some within the field.

- Preclusion: (some of) the activities called inclusive innovation are not actually innovation, and should not be the concern of innovation researchers, policy-makers, or practitioners.

These perspectives are a reminder that models contain the norms and values of those who create them, shaping the thinking of those who use them: what Fressoli et al. refer to as the 
'framing' power of models. Examples would include the assumption of innovation platforms that participative approaches to innovation are beneficial or the assumption of grassroots innovation that relatively excluded groups are a source of valuable new ideas. Exposing this framing would require answers to questions such as:

- Who creates this model?

- What is included and what is excluded in the model's abstraction?

- What assumptions does the model make?

- Who benefits from the model?

Alongside these issues of inherent framing, we can also recognize 'framing-in-use': the particular way in which the models are circulated and applied. For example, the extent to which women are or are not included in innovation platforms or the interpreted consumer market for frugal innovations. Again, we could ask questions about who interprets, uses, and promotes particular forms of each model; why they do this; and what impact this has.

One could regress the recognition of framing right up to the very notion of innovation itself but a balance must be struck. Thus, while all six papers in the special issue have an element of critique, three (Voeten and Naudé, Foster and Heeks, and Swaans et al.) restrict this to questioning the operation of each model in practice. But the other three do move further to challenge the models in some way; not just accepting them but unpacking the models and their foundation. Papaioannou reveals the different philosophical underpinnings behind different models of inclusive innovation. Cullen et al. spotlight the power dynamics that shape the formation, interpretation, and implementation of inclusive innovation models. Fressoli et al. expose different ways in which inclusive (specifically grassroots) innovation can be framed, and then track what happens when different framings of inclusive innovation models encounter one another.

\section{Contribution of the special issue}

As just noted, and unlike the other five papers, Theo Papaioannou's paper - 'How Inclusive Can Innovation and Development be in the 21st Century?' - does not restrict itself to a single model of inclusive innovation. It studies two: frugal innovation and grassroots innovation.

As per the definition above, the core focus of the frugal innovation model is minimization of resource use, cost, and complexity. At best, it might be placed at Level 1 (intention) or just possibly Level 2 (consumption) of the inclusive innovation ladder. First, because marginalized, lowincome consumers are not always the target of frugal innovation. The Tata Nano car is an oft-cited example of frugal innovation but - with a minimum price of c. US\$2,500 - it is way beyond the means of the more than 3 billion who live on less than US\$2.5 per day (World Bank 2013b). Second, because the focus of the frugal innovation model is far more on the process and products of innovation than it is on the consumers and impact of those innovations. Of course, there are multiple interpretations of the frugal innovation model but, for most, any inclusivity would be a by-product rather than an inherent feature.

The grassroots innovation model also focuses on the innovation process but brings the innovator themselves to the fore; that innovator coming from a marginalized group. It therefore sites itself at Level 4 (process) of the inclusive innovation ladder by seeing inclusivity to require the involvement of marginalized group members in early stages of the innovation lifecycle. It places the marginalized innovator at the heart of the process, both exploiting and further enhancing their innovation capabilities.

Papaioannou's paper resonates with the idea of different understandings of inclusivity, as per the ladder model, but it takes its analysis right back to philosophical underpinnings of 
development. It can particularly be seen to offer new insights into inclusive innovation models from the foundations of development studies, exploring what inclusivity means through lenses of cosmopolitanism, capability theory, and the basic needs approach. Each of these three perspectives presents a different yardstick with which to assess the inclusivity of inclusive innovation models, and Papaioannou argues the potential greater value of the basic needs perspective. His main contribution, therefore, is to remind us that inclusive innovation models are not valueneutral and that it thus behoves those working in this domain to be more explicit about the underlying norms and values which shape their approach to inclusive innovation.

Papaioannou highlights the importance but also current shortcomings of public policy in delivering different visions of inclusive innovation. The paper 'Regulating the Negative Externalities of Enterprise Cluster Innovations: Lessons from Vietnam' by Jaap Voeten and Wim Naudé picks up this theme of policy shortcomings. It does this within the context of the cluster innovation model in Vietnamese craft villages.

We could associate the cluster innovation model with inclusive innovation Level 4 (process) since it focuses on the role of micro-entrepreneurs in innovation, and with Level 5 (structure) since its main interest is the co-located network structure within which the innovation is developed. The strength of this association with Level 4/5 is qualified because there is no necessary connection between innovation clusters and low-income community micro-enterprises. This is more a descriptive model of innovation structure and relations than a prescriptive model of inclusivity, and the cluster could be of much larger firms.

Where applying to micro-enterprises, as in Voeten and Naudé's paper, clusters are often described as involving those on lower rather than lowest incomes. Many involved, though, are still poor - Sakata (2013) cites average Vietnamese craft village incomes in the 2000s as US \$22-66 per month depending on type of craft, compared to average rural farming income of US\$17 - and hence it is appropriate to label this as an inclusive innovation model in this instance.

The insights into the cluster model provided by the paper come from an inductive and longitudinal research approach implemented over three years. What this approach found was the negative environmental and social externalities that can materialize from this type of inclusive innovation, and the limited role played by external regulation. The authors find that not just innovation but also an 'internal regulation' of externalities can emerge from inclusive clusters, but in many cases only if facilitated by some degree of external intervention.

The cluster-based view of innovation can be understood as one example of the broader notion of systems of innovation: collections of organizations and institutions which act together to innovate. Traditionally associated only with conventional innovation, systems of innovation are now being identified in relation to inclusive innovation (Foster and Heeks 2013), and this insight underpins the next two papers in the special issue.

Christopher Foster and Richard Heeks' paper 'Nurturing User-Producer Interaction: Inclusive Innovation Flows in a Low-Income Mobile Phone Market' extracts one part from the systems of innovation model - user-producer interaction - which is applied to mobile phone-related innovation in Kenya. Being a model of relations between actors, it has commonalities with the cluster innovation model. It can be associated with Level 4 (process) innovation inclusivity, though it sees intermediaries based in and around low-income communities, rather than end users, as sitting alongside lead-firm producers as innovators. And it could be associated with Level 5 (structure) except that the model represents just one part of a much larger structural whole that would need to be inclusive for this label to properly apply.

Indeed, the main contribution of the paper is to identify two different structural mechanisms for linking producers and users in cases of inclusive innovation: hierarchical vs. market mechanisms. Where the former allows lead firms greater control, it reduces the opportunity for the localized, user-oriented innovations that are vital in diffusing new goods and services to 
BoP consumers. Market mechanisms allow greater freedom for such innovation but also for less beneficial innovations, and reduce the potential for 'reverse' flows of learning and innovation from users to producers. Either case, the authors argue, will benefit from enhancing demand-side capability, recognizing the trade-offs between control and freedom for local innovation, and finding ways to reduce the distance between low-income users and innovation producers.

'Operationalising Inclusive Innovation: Lessons from Innovation Platforms in Livestock Value Chains in India and Mozambique' - a paper by Kees Swaans, Birgit Boogaard, Ramkumar Bendapudi, Hailemichael Taye, Saskia Hendrickx, and Laurens Klerkx - continues the systems of innovation theme. It analyses the model of innovation platforms from an inclusive systems of innovation perspective.

The innovation platforms model sits relatively convincingly at inclusive innovation Level 5 (structure). 'Convincingly' because it is a structural model seeking to include the poor usually farmers since innovation platforms is a model applied largely in agriculture to date alongside other stakeholders in innovation processes. 'Relatively' because even multi-stakeholder innovation platforms are only sub-structures within the wider structure of national agricultural systems of innovation.

Swaans et al. find that the wider context bled into the functioning of innovation platforms, which they track over a three-year period in India and Mozambique. From this, they identify a set of key issues likely to emerge with innovation platforms - around the nature of actors and their relations, the incentives for innovation, the mechanisms for learning, etc - which then generate some recommendations for practice.

The motif of contextual influences on innovation platforms continues in the next paper: 'An Analysis of Power Dynamics Within Innovation Platforms for Natural Resource Management' by Beth Cullen, Josephine Tucker, Katherine Snyder, Zelalem Lema, and Alan Duncan. In this case, though, rather than deriving insights inductively from practice, the authors derive them deductively through application to innovation platforms in Ethiopia of the 'power cube' framework. Also based around a three-year longitudinal study, three political dimensions are analysed: the shaping of the space within which inclusive innovation takes place; the forms of power - both overt and hidden - which are exercised during inclusive innovation stakeholder selection and interaction, decision-making and implementation; and the different levels of power manifest within inclusive innovation initiatives such as innovation platforms.

Power and its exercise via politics are seen to be central determinants of the outcomes of inclusive innovation models. Inclusive innovation models often challenge existing power structures but, as noted above, those models are typically just sub-structures within a much wider whole. Those wider power structures may continue to dominate, reproducing themselves within the practice of inclusive innovation models and potentially generating innovation without inclusion; at least without Level 5-type (structural) inclusion.

This issue of power is also explored in the final paper of the special issue, 'When Grassroots Innovation Movements Encounter Mainstream Institutions: Implications for Models of Inclusive Innovation' by Mariano Fressoli, Elisa Arond, Dinesh Abrol, Adrian Smith, Adrian Ely, and Rafael Dias. The authors take what can be seen as a Level 6 (post-structural) perspective, understanding the framing of models of inclusive innovation; that is, the way in which meanings and narratives are produced. They then trace these as one particular model - that of grassroots innovation - meets more mainstream innovation institutions in examples from Brazil and India.

These encounters produce two types of results. Grassroots innovation may be inserted into the innovation mainstream but possibly in the form of a scaled, de-contextualized model that betrays some notions of inclusivity. Or grassroots innovation may mobilize and resist, still seeking to provide an alternative to conventional innovation. In either case, the mainstream still dominates 
innovation discourse and structures. So, at most, a relatively small space for Level 5 or Level 6 inclusion is created. However, Fressoli et al. do demonstrate that inclusive innovation and mainstream innovation are not separate bubbles. They interact and influence each other and the potential is there for mainstream innovation models to become more inclusive. Indeed, the suggestion here is that we should be less concerned with models and more concerned with the process of modelling: the actors and means by which models of inclusive innovation are constructed.

\section{Lessons for the future}

From any research outputs, one can seek to extract lessons for practice, for policy, and for future research. Individual papers in this special issue have something to say about practice: Voeten and Naudé recommend ways to strengthen local regulation of inclusive innovation; Foster and Heeks recommend ways to improve user-producer interaction; Swaans et al. offer guidance for innovation platform managers, etc. But an overall theme is the way that horizons for good practice expand as one's perspective moves up the inclusive innovation ladder. A Level 3 view on practice will focus simply on improvements to design and use of new goods and services. A Level 4 view will extend this to improve the process by which those innovations are designed, developed, and diffused. A Level 5 view will focus practitioners on recommendations around the structuring of those processes. And the advised starting point from a Level 6 perspective is an examination and understanding of the frames of knowledge which key actors bring to inclusive innovation. We see examples of all these in different papers of the special issue.

Similar lessons can be drawn about policy: alongside the occasional direct recommendation on policy content, the papers guide the reader more to consider policy process and structure. If power structures and framings of inclusive innovation models are central to their ultimate outcomes, the same must also be true of policy for inclusive innovation. Rather than advocating a one-size-fits-all policy menu, the papers presented here thus suggest a more reflective point of departure for policy that seeks first to understand the actors, perspectives, and politics of inclusive innovation.

Lessons for future research can begin with the disciplinary map shown in Figure 3. This argues that, in simple terms, inclusive innovation can be understood as the intersection of innovation studies (IS) and development studies, with each of those fed by broader cognate disciplines.

We can interpret this map in two ways. It is a guide to sources of conceptual frameworks that can inform the study of inclusive innovation models. And it is a guide to the intellectual audiences for research on inclusive innovation models. Inclusive innovation research has been fairly good at engaging with IS; for example, making use of IS frameworks such as systems of innovation (as do the papers by Foster and Heeks, and Swaans et al.) and ensuring a presence at fora such as the Globelics annual conferences.

To date, inclusive innovation research has been less good at engagement with development studies, but this special issue provides some pointers. Papaioannou's paper shows directly and foundationally how this can happen, and other papers offer possible routes by speaking a language that development studies audiences would understand: of externalities and regulation (Voeten and Naudé), of power and politics (Cullen et al.), and of framing (Fressoli et al.). The importance of this engagement must be stressed. As previously explained, inclusive innovation will have a presence in the Post-2015 Development Agenda, and development-based policy and practice audiences will look to research for guidance.

We already have some sense of priority guidance topics from a research demand study that surveyed a policy and practice audience, as summarized in Table 1 from three perspectives (Heeks et al. 2013). 


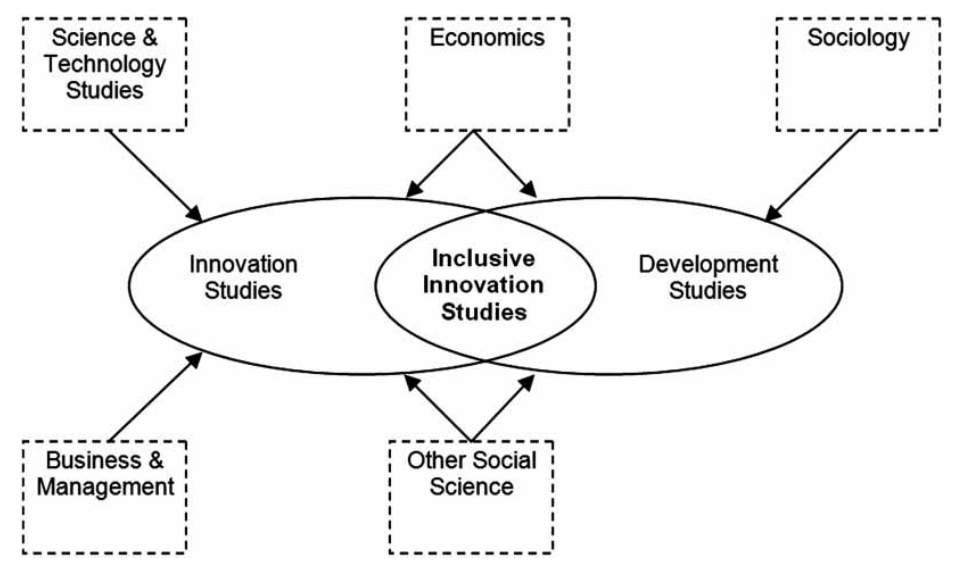

Figure 3. Disciplinary foundations for inclusive innovation research.

Table $1 . \quad$ Summary of inclusive innovation research priorities.

\begin{tabular}{ll}
\hline Perspective & \multicolumn{1}{c}{ Research priority } \\
\hline Stakeholder & Policy for inclusive innovation \\
& Grassroots innovation \\
Systemic & Inclusive innovation intermediaries \\
& Basics of inclusive innovation \\
& New models of inclusive innovation \\
Process & Informatics and inclusive innovation \\
& Benchmarks for inclusive innovation \\
& Readiness for inclusive innovation \\
& Inclusive innovation good practice \\
& Scaling inclusive innovations \\
& Impact evaluation of inclusive innovation \\
\hline
\end{tabular}

The papers presented in this special issue have provided new insights into a number of these topic areas, not least of course 'New Models of Inclusive Innovation'. The challenge ahead will be building a programme of research sufficient to generate a critical mass of new evidence and ideas for each one of these inclusive innovation research priorities. But policy and practice must not be the only guides for such a research programme. In the academic tradition, future research must also 'speak truth to power' and interrogate further the framing and politics of inclusive innovation models.

\section{Acknowledgements}

The 'New Models of Innovation for Development' workshop from which papers for this special issue were selected was financially supported by the Institute for Development Policy and Management, and the Manchester Institute of Innovation Research; both of the University of Manchester, UK. The workshop was supported by the UK Development Studies Association. The editors also wish to thank the attendees and rapporteurs of the workshop, and the anonymous reviewers for the papers in this special issue. Each of the papers went through two rounds of review and revision, a first round of non-blind rapporteur and workshop organizer comments at the time of the workshop, and then a second round of double-blind review by two referees as part of the special issue process. 


\section{Note}

1. Publication date data from Google Scholar search term 'inclusive innovation' excluding patents and citations.

\section{References}

Chataway, J., R. Hanlin, and R. Kaplinsky. 2014. "Inclusive Innovation: An Architecture for Policy Development." Innovation and Development 4 (1): 33-54.

Codagnone, C. ed. 2009. Vienna Study on Inclusive Innovation for Growth and Cohesion. Brussels: European Commission.

Cozzens, S., E. Kallerud, L. Ackers, B. Gill, J. Harper, T. S. Pereira, and N. Zarb-Adami. 2007. Problems of Inequality in Science, Technology, and Innovation Policy, Working Paper 5, James Martin Institute, University of Oxford, UK.

Cozzens, S., and J. Sutz. 2012. Innovation in Informal Settings: A Research Agenda. Ottawa: IDRC.

Foster, C., and R. Heeks. 2013. "Conceptualising Inclusive Innovation: Modifying Systems of Innovation Frameworks to Understand Diffusion of New Technology to Low-Income Consumers." European Journal of Development Research 25 (3): 333-355.

George, G., A. M. McGahan, and J. Prabhu. 2012. "Innovation for Inclusive Growth: Towards a Theoretical Framework and Research Agenda." Journal of Management Studies 49 (4): 661-683.

Goel, V. K. 2011. "Instruments to Promote Inclusive Innovation." Paper presented at Inclusive Innovation Workshop, Bangkok, March 4.

Heeks, R. 2014. From the MDGs to the Post-2015 Agenda: Analysing Changing Development Priorities, IDPM Development Informatics Working Paper no.56, University of Manchester, UK.

Heeks, R., M. Amalia, R. Kintu, and N. Shah. 2013. Inclusive Innovation: Definition, Conceptualisation and Future Research Priorities, IDPM Development Informatics Working Paper no.53, University of Manchester, UK.

IDRC. 2011. Innovation for Inclusive Development. Ottawa: IDRC.

Jamison, A. 2006. "Social Movements and Science." Science as Culture 15 (1): 45-59.

Joseph, K. J. 2014. "Exploring Exclusion in Innovation Systems." Innovation and Development 4 (1): 73-90.

Kaplinsky, R. 2011. "Schumacher Meets Schumpeter: Appropriate Technology Below the Radar." Research Policy 40 (2): 193-203.

Klochikhin, E. 2012. "Linking Development and Innovation: What does Technological Change bring to the Society?" European Journal of Development Research 24 (1): 41-55.

Lazonick, W., and M. Mazzucato. 2013. "The Risk-Reward Nexus in the Innovation-Inequality Relationship." Industrial and Corporate Change 22 (4): 1093-1128.

OAPM. 2011. Towards a More Inclusive and Innovative India. Office of the Advisor to the Prime Minister, Government of India, New Delhi.

OECD. 2005. Oslo Manual: Guidelines for Collecting and Interpreting Innovation Data. Paris: OECD.

OECD. 2013. Innovation and Inclusive Development. Paris: OECD. http://www.oecd.org/sti/inno/oecdinclusive-innovation.pdf

Ramani, S. V., S. SadreGhazi, and G. Duysters. 2012. "On the Diffusion of Toilets as Bottom of the Pyramid Innovation." Technological Forecasting and Social Change 79 (4): 676-687.

Sakata, S. 2013. "Rural Industries in Northern Vietnam." In: Vietnam's Economic Entities in Transition, edited by S. Sakata, 204-226. Basingstoke: Palgrave Macmillan.

Santiago, F. 2014. "Innovation for Inclusive Development." Innovation and Development 4 (1): 1-4.

Stiglitz, J. E. 2012. The Price of Inequality. New York, NY: WW Norton.

UNDP. 2014. Inclusive Development. New York, NY: UNDP. http://www.undp.org/content/undp/en/home/ ourwork/povertyreduction/focus_areas/focus_inclusive_development/

World Bank. 2012. Introductory Note, presented at Regional Inclusive Innovation Policy Forum, Beijing, May 23-24.

World Bank. 2013a. Shared Prosperity. Washington, DC: World Bank. http://www.worldbank.org/en/news/ feature/2013/05/08/shared-prosperity-goal-for-changing-world

World Bank. 2013b. World Development Report 2014. Washington, DC: World Bank. 